\title{
INITIAL ABILITY READING JAVANESE SCRIPT TO PARTICIPANTS IN CLASS IV SDN KUTOREJO I TUBAN ON MATERIAL SANDHANGAN
}

\author{
Wendri Wiratsiwi, Mega Puspita Sari, Lulu Anggi Rhosalia \\ wendriwiratsiwi3489@gmail.com,meemega@yahoo.com, luluanggie@gmail.com \\ Pendidikan Guru Sekolah Dasar \\ Fakultas Keguruan dan Ilmu Pendidikan \\ Universitas PGRI Ronggolawe Tuban
}

\begin{abstract}
A preliminary research was conducted which was aimed to determine the ability of early reading of Javanese literacy students class IV SDN Kutorejo I Tuban on sandhangan material consisting of three indicators namely the accuracy of voicing writing, pronunciation, and fluency. This preliminary research is part of the interactive multimedia development research of Arawa (Aplikasi Aksara Jawa) for learning reading Javanese script of sandhangan material. The first literacy test of Javanese literacy test consists of 10 words of Javanese script that has been added with sandhangan swara, sandhangan wyanjana, and sandhangan penyigeg-wanda. Early reading ability of Javanese script analyzed is reading skill of Javanese learner of class IV student of SDN Kutorejo I Tuban academic year 2017/2018 before implemented an interactive multimedia development Arawa (Aplikasi Aksara Jawa) that allegedly can improve the reading ability of Javanese learner. The result of the analysis showed that the early reading ability of students in grade IV of SDN Kutorejo I which got the score of KKM or $\geq 70$ was $27.02 \%$ (10 students) with the highest score 82 and $72,98 \%$ (27 students) below 70 with the lowest score of 25

Keywords:Initial ability, reading Javanese script, sandhangan
\end{abstract}

\section{KEMAMPUAN AWAL MEMBACA AKSARA JAWA SISWA KELAS IV SDN KUTOREJO I TUBAN MATERI SANDHANGAN}

\begin{abstract}
Abstrak: Telah dilakukan penelitian awal yang bertujuan mengetahui kemampuan awal membaca aksara Jawa siswa kelas IV SDN Kutorejo I Tuban pada materi sandhangan yang terdiri dari tiga indikator yaitu ketepatan menyuarakan tulisan, pelafalan, dan kelancaran. Penelitian awal ini merupakan bagian dari penelitian pengembangan multimedia interaktif Arawa (Aplikasi Aksara Jawa) untuk pembelajaran membaca aksara Jawa materi sandhangan. Tes kemampuan awal membaca aksara Jawa berupa tes lisan yang disusun berjumlah 10 kata aksara Jawa yang sudah diimbuhi sandhangan swara, sandhangan wyanjana, dan sandhangan penyigeg-wanda. Kemampuan awal membaca aksara Jawa yang dianalisis merupakan kemampuan membaca aksara Jawa siswa kelas IV SDN Kutorejo I Tuban TP. 2017/2018 sebelum diterapkan suatu pengembangan multimedia interaktif Arawa (Aplikasi Aksara Jawa) yang diduga dapat meningkatkan kemampuan membaca aksara Jawa siswa. Hasil analisis menunjukkan bahwa kemampuan awal membaca aksara siswa kelas IV SDN Kutorejo I yang mendapat nilai memenuhi KKM atau $\geq 70$ adalah sebesar 27,02\% ( 10 siswa) dengan nilai tertinggi 82 dan $72,98 \%$ ( 27 siswa) siswa lainnya mendapat nilai di bawah 70 dengan nilai terendah 25 .
\end{abstract}

Kata Kunci : Kemampuan awal, membaca aksara Jawa, sandhangan 
Wendri, Mega, Lulu, Kemampuan Awal Membaca Aksara...

\section{PENDAHULUAN}

Dalam rangka mengimplementasikan UU No.20 Tahun 2003 tentang Sistem Pendidikan Nasional Pasal 37 Ayat (1) yang menyebutkan kurikulum pendidikan dasar dan menengah wajib memuat muatan lokal, maka sebagai upaya pengembangan, pembinaan, pelestarian bahasa, sastra, dan budaya jawa, pengembangan budi pekerti serta kepribadian di kalangan para siswa pendidikan dasar dan menengah, diperlukan kurikulum muatan lokal sebagai acuan dalam kegiatan mengajar Bahasa Jawa. Untuk itu sesuai Permendiknas Nomor 22 tentang Standar Isi, muatan lokal juga merupakan salah satu komponen dalam struktur kurikulum.

Bahasa Jawa sebagai salah satu mata pelajaran muatan lokal dan kebudayaan Jawa yang masih bertahan sebagai salah satu upaya agar kebudayaan Jawa tetap lestari. Mata pelajaran Bahasa Jawa dipelajari oleh siswa SD sampai dengan SMA. Ada lima kompetensi dasar yang harus dicapai siswa dalam pembelajaran Bahasa Jawa, yaitu mendengarkan, berbicara, membaca, menulis, dan sastra Jawa. Salah satu materi pelajaran dari mata pelajaran Bahasa Jawa yaitu aksara Jawa dengan kompetensi dasar membaca dan menulis.

Seseorang akan memperoleh informasi, pengetahuan, dan pengalaman melalui kegiatan membaca. Membaca merupakan keterampilan yang kompleks. Dengan kata lain, membaca mencakup tiga komponen, yaitu: (1) pengenalan awal terhadap aksara dan tanda baca, (2) korelasi aksara dan tanda baca dengan unsur linguistik formal, dan (3) hubungan lanjut dari komponen pertama dan kedua dengan makna. (Tarigan, 2008).

Dalam pembelajaran membaca aksara Jawa, siswa harus dapat menguasai keterampilan membaca bacaan beraksara Jawa. Syarat agar siswa dapat terampil membaca bacaan beraksara Jawa yaitu siswa harus mengenal aksara Jawa dan memahami cara membacanya.

Menurut Prihantoro (2011) bahasa Jawa sebagai bahasa tulisan dapat ditulis menggunakan aksara Jawa dan aksara Latin. Membelajarkan aksara Jawa merupakan suatu tantangan tersendiri bagi guru. Dewasa ini aksara Jawa sudah jarang digunakan dalam kehidupan sehari-hari. Pada kenyataannya aksara Jawa pada saat ini lebih digunakan sebagai makna simbolis. Sesuai dengan standar kompetensi dan kompetensi dasar yang telah ditetapkan dalam kurikulum mata pelajaran Bahasa Jawa, aksara Jawa mulai dikenalkan kepada siswa kelas IV SD semester I. Pada awal permulaan, siswa diajarkan aksara Jawa tanpa pasangan atau yang disebut aksara Jawa legena, yang terdiri dari 20 huruf dasar dalam aksara Jawa. Selanjutnya, pada semester 2 siswa mulai diperkenalkan sandhangan dan panyigeg sebagai tanda baca pada aksara Jawa. Aksara Jawa digunakan secara bersamaan dengan pasangan, sandhangan, dan panyigeg agar dapat membentuk kata yang bermakna.

Aktivitas membaca aksara Jawa merupakan suatu proses memahami atau mencari makna dari simbol-simbol berupa huruf dengan melibatkan indera penglihatan dengan tujuan untuk memperoleh informasi yang menitikberatkan pada kegiatan 
Wendri, Mega, Lulu, Kemampuan Awal Membaca Aksara...

mengucapkan dan memahami makna lambang-lambang dalam bentuk aksara Jawa. Dalam aktivitas membaca aksara Jawa keterampilan membaca dapat dilihat dari aspek ketepatan pengucapan tulisan aksara Jawa, ketepatan pelafalan, dan kelancaran dalam membaca.

Aspek ketepatan menyuarakan tulisan digunakan untuk menilai ketepatan siswa dalam mengucapkan setiap kata yang ditulis dengan aksara Jawa. Aspek lafal digunakan untuk menilai ketepatan siswa dalam mengucapkan bunyi bahasa (fonem) dalam aksara Jawa. Hal ini perlu dinilai karena dalam aksara Jawa terdapat fonem yang diucapkan berbeda dengan tulisannya, misalnya vokal a ada yang diucapkan sebagai a seperti dalam kata "mama", misalnya pasar. Adapula yang diucapkan sebagai o seperti dalam kata "kokoh", misalnya punakawan dibaca punokawan. Aspek kelancaran digunakan untuk menilai keberhasilan siswa dalam mempelajari aksara Jawa.

\section{METODE}

Jenis penelitian adalah penelitian deskriptif dengan tujuan mendeskripsikan kemampuan awal membaca aksara Jawa siswa kelas IV SDN Kutorejo I Tuban TP. 2017/2018 sebelum diterapkan suatu pengembangan multimedia interaktif Arawa (Aplikasi Aksara Jawa). Jenis penelitian digunakan untuk mengambarkan kemampuan awal membaca aksara Jawa siswa materi sandhangan dengan tiga pengukuran indikator membaca aksara Jawa. Penelitian dilakukan pada bulan April 2018 di SDN Kutorejo I Tuban. Subjek penelitian adalah siswa kelas IV SDN Kutorejo I Tuban TP. 2017/2018. Kemampuan awal membaca aksara Jawa diketahui dari hasil tes lisan yang kemudian dianalisis persentase jawaban siswa sesuai dengan indikator yang diadaptasi Indrawan (2014).

\section{HASIL}

Tahapan awal dari penelitian adalah penyusunan tes kemampuan membaca aksara Jawa dan menggunakan indikator yang diadaptasi dari Indrawan (2014). Soal tes lisan dibuat peneliti dan disesuaikan dengan materi sandhangan. Sebelum dilakukan pelaksanaan tes kemampuan membaca aksara Jawa, soal tes divalidasi oleh ahli yang berupa satu orang dengan keahlian bahasa Jawa dan satu orang dosen bidang pendidikan. Adapun gambaran umum atau kategori kemampuan membaca aksara Jawa seperti Tabel 1.

Tabel 1. Pedoman Penilaian Membaca Aksara Jawa

\begin{tabular}{|c|l|c|l|}
\hline No & Aspek yang diamati & Skor & \multicolumn{1}{|c|}{ Kriteria } \\
\hline 1 & Ketepatan menyuarakan & 1 & Jika tepat menyuarakan satu kata dalam kalimat \\
\cline { 3 - 4 } & tulisan & 2 & Jika tepat menyuarakan dua kata dalam kalimat \\
\cline { 3 - 4 } & & 3 & Jika tepat menyuarakan tiga kata dalam kalimat \\
\cline { 3 - 4 } & & 4 & Jika tepat menyuarakan empat kata dalam kalimat \\
\hline 2 & \multirow{2}{*}{ Lafal } & 1 & Jika benar dalam melafalkan satu kata dalam kalimat \\
\cline { 3 - 4 } & & 2 & Jika benar dalam melafalkan dua kata dalam kalimat \\
\hline
\end{tabular}


Wendri, Mega, Lulu, Kemampuan Awal Membaca Aksara...

\begin{tabular}{|c|l|c|l|}
\hline No & Aspek yang diamati & Skor & \multicolumn{1}{|c|}{ Kriteria } \\
\hline & & 3 & Jika benar dalam melafalkan tiga kata dalam kalimat \\
\cline { 3 - 4 } & & 4 & Jika benar dalam melafalkan empat kata dalam kalimat \\
\hline 3 & \multirow{2}{*}{ Kelancaran } & 1 & Jika lancar mengucapkan satu kata tanpa pengulangan \\
\cline { 3 - 5 } & & 2 & Jika lancar mengucapkan dua kata tanpa pengulangan \\
\cline { 3 - 5 } & & 3 & Jika lancar mengucapkan tiga kata tanpa pengulangan \\
\cline { 3 - 5 } & & 4 & Jika lancar mengucapkan empat kata tanpa pengulangan \\
\hline
\end{tabular}

Untuk selanjutnya, nilai dihitung dengan menggunakan persen dengan menggunakan pedoman penskoran:

$$
\text { Nilai }=\frac{\text { Skor yang diperoleh }}{\text { Skor Maksimal }} \times 100
$$

Setelah diperoleh nilai, kemudian nilai tersebut diberi makna ke dalam bentuk kualitatif yang dimasukkan dalam rentangan hubungan antara skala angka dengan skala huruf yang mengacu pada pendapat Arikunto (2010).

Tabel 2. Hubungan antara Skala Angka dan Skala Huruf

\begin{tabular}{|c|c|c|}
\hline Rentang Angka & Huruf & Keterangan \\
\hline $80-100$ & A & Sangat Baik \\
\hline $70-79$ & B & Baik \\
\hline $60-69$ & C & Cukup Baik \\
\hline $50-59$ & D & Kurang Baik \\
\hline $0-49$ & E & Tidak baik \\
\hline
\end{tabular}

Berikut di sajikan data tentang kemampuan awal membaca aksara Jawa siswa kelas IV SDN Kutorejo I Tuban dalam Tabel 3 di bawah ini:

Tabel 3 Nilai Kemampuan Awal Membaca Aksara Jawa

\begin{tabular}{|c|c|c|c|c|c|c|c|c|c|c|c|c|}
\hline Kode & X1 & X2 & X3 & X4 & X5 & X6 & X7 & X8 & X9 & X10 & Skor & Nilai \\
\hline K-01 & 3 & 3 & 3 & 3 & 3 & 3 & 3 & 3 & 3 & 3 & 30 & 25 \\
\hline K-02 & 3 & 3 & 3 & 3 & 3 & 3 & 3 & 3 & 3 & 3 & 30 & 25 \\
\hline K-03 & 5 & 6 & 4 & 4 & 4 & 4 & 4 & 4 & 4 & 4 & 43 & 35,83333 \\
\hline K-04 & 5 & 6 & 5 & 5 & 5 & 5 & 5 & 5 & 5 & 5 & 51 & 42,5 \\
\hline K-05 & 9 & 10 & 10 & 10 & 10 & 9 & 10 & 10 & 10 & 10 & 98 & 81,66667 \\
\hline K-06 & 9 & 10 & 9 & 9 & 9 & 7 & 9 & 7 & 9 & 9 & 87 & 72,5 \\
\hline K-07 & 5 & 6 & 4 & 5 & 5 & 4 & 5 & 4 & 5 & 5 & 48 & 40 \\
\hline K-08 & 5 & 5 & 5 & 3 & 3 & 3 & 3 & 3 & 3 & 3 & 36 & 30 \\
\hline K-09 & 9 & 10 & 9 & 8 & 9 & 8 & 9 & 8 & 9 & 9 & 88 & 73,33333 \\
\hline K-10 & 6 & 6 & 5 & 5 & 5 & 4 & 5 & 4 & 5 & 5 & 50 & 41,66667 \\
\hline K-11 & 3 & 3 & 3 & 3 & 3 & 3 & 3 & 3 & 3 & 3 & 30 & 25 \\
\hline K-12 & 5 & 6 & 6 & 5 & 5 & 4 & 5 & 4 & 5 & 5 & 50 & 41,66667 \\
\hline K-13 & 9 & 10 & 9 & 9 & 9 & 6 & 6 & 6 & 9 & 9 & 82 & 68,33333 \\
\hline K-14 & 6 & 7 & 5 & 6 & 5 & 5 & 6 & 5 & 6 & 6 & 57 & 47,5 \\
\hline K-15 & 5 & 6 & 5 & 5 & 5 & 3 & 4 & 3 & 4 & 4 & 44 & 36,66667 \\
\hline K-16 & 3 & 3 & 3 & 3 & 3 & 3 & 3 & 3 & 3 & 3 & 30 & 25 \\
\hline K-17 & 6 & 6 & 5 & 5 & 5 & 4 & 6 & 5 & 6 & 6 & 54 & 45 \\
\hline K-18 & 3 & 3 & 3 & 3 & 3 & 3 & 3 & 3 & 3 & 3 & 30 & 25 \\
\hline K-19 & 5 & 5 & 5 & 5 & 5 & 4 & 5 & 4 & 5 & 5 & 48 & 40 \\
\hline
\end{tabular}


Wendri, Mega, Lulu, Kemampuan Awal Membaca Aksara...

\begin{tabular}{|c|c|c|c|c|c|c|c|c|c|c|c|c|}
\hline Kode & X1 & X2 & X3 & X4 & X5 & X6 & X7 & X8 & X9 & X10 & Skor & Nilai \\
\hline K-20 & 9 & 10 & 10 & 10 & 10 & 8 & 10 & 10 & 10 & 10 & 97 & 80,83333 \\
\hline K-21 & 6 & 6 & 7 & 5 & 5 & 6 & 6 & 6 & 6 & 6 & 59 & 49,16667 \\
\hline K-22 & 3 & 3 & 3 & 3 & 3 & 3 & 3 & 3 & 3 & 3 & 30 & 25 \\
\hline K-23 & 9 & 9 & 9 & 9 & 9 & 8 & 9 & 7 & 7 & 8 & 84 & 70 \\
\hline K-24 & 5 & 6 & 6 & 5 & 5 & 4 & 5 & 4 & 5 & 5 & 50 & 41,66667 \\
\hline K-25 & 9 & 10 & 9 & 9 & 10 & 9 & 9 & 9 & 10 & 10 & 94 & 78,33333 \\
\hline K-26 & 6 & 9 & 9 & 9 & 6 & 5 & 6 & 5 & 6 & 6 & 67 & 55,83333 \\
\hline K-27 & 9 & 10 & 8 & 8 & 8 & 7 & 8 & 8 & 8 & 8 & 82 & 68,33333 \\
\hline K-28 & 9 & 9 & 8 & 8 & 8 & 7 & 8 & 8 & 8 & 8 & 81 & 67,5 \\
\hline K-29 & 9 & 6 & 6 & 5 & 5 & 4 & 5 & 4 & 5 & 5 & 54 & 45 \\
\hline K-30 & 9 & 9 & 9 & 8 & 8 & 6 & 7 & 6 & 8 & 8 & 78 & 65 \\
\hline K-31 & 8 & 9 & 10 & 8 & 8 & 7 & 8 & 8 & 8 & 8 & 82 & 68,33333 \\
\hline K-32 & 8 & 6 & 9 & 9 & 9 & 6 & 5 & 6 & 5 & 6 & 69 & 57,5 \\
\hline K-33 & 7 & 10 & 9 & 9 & 10 & 9 & 9 & 9 & 10 & 10 & 92 & 76,66667 \\
\hline K-34 & 8 & 9 & 9 & 9 & 9 & 8 & 9 & 8 & 7 & 8 & 84 & 70 \\
\hline K-35 & 8 & 10 & 10 & 10 & 10 & 8 & 10 & 10 & 10 & 8 & 94 & 78,33333 \\
\hline K-36 & 6 & 6 & 7 & 5 & 5 & 4 & 6 & 5 & 6 & 6 & 56 & 46,66667 \\
\hline K-37 & 10 & 10 & 10 & 8 & 10 & 9 & 9 & 9 & 10 & 10 & 95 & 79,16667 \\
\hline & \multicolumn{10}{|c|}{ Jumlah } \\
\hline \multicolumn{10}{|c|}{} \\
\hline
\end{tabular}

Keterangan :

$\mathrm{K}$ - $\quad$ : siswa ke -

$\mathrm{X}-\quad$ : soal ke -

\section{PEMBAHASAN}

Hasil tes kemampuan membaca aksara Jawa siswa kelas IV SDN Kutorejo I Tuban menunjukkan bahwa kemampuan awal membaca aksara Jawayaitu 27,02\% ( 10 siswa) sudah memenuhi KKM atau mendapat nilai $\geq 70$ dengan nilai tertinggi 82 dan $72,98 \% 27$ siswa) siswa lainnya mendapat nilai dibawah 70 dengan nilai terendah 25 . Sedangkan rata-rata kelasnya adalah 52,56.

Berdasarkan Tabel 3 di atas, hanya ada 2 siswa yang tergolong mempunyai kemampuan membaca sangat baik atau memiliki nilai A $(5,4 \%)$. Siswa yang tergolong memiliki kemampuan membaca aksara Jawa yang baik atau bernilai B hanya 8 anak $(21,6 \%)$, begitu pula siswa yang berkemampuan membaca aksara Jawa cukup baik atau memiliki nilai $\mathrm{C}$ yaitu 5 anak $(13,5 \%)$. Siswa yang memiliki kemampuan membaca aksara Jawa kurang baik atau memiliki D berjumlah 2 siswa $(5,4 \%)$. Kemudian siswa yang kemampuan membaca aksara Jawanya tidak baik atau memiliki nilai E merupakan jumlah terbanyak, yaitu 20 siswa $(54,05 \%)$.

Berdasarkan penjelasan tersebut, dapat disimpulkan bahwa pada kegiatan pretest atau pratindakan kemampuan membaca aksara Jawa siswa kelas IV A tidak baik. Hal ini terlihat dari banyaknya siswa yang memiliki nilai $\mathrm{E}$ atau kemampuan membaca aksara Jawa yang tidak baik.

Ketidakmampuan siswa dalam membaca aksara Jawa membuktikan bahwa pembelajaran membaca aksara Jawa di SDN Kutorejo I kelas IV belum berjalan secara 
Wendri, Mega, Lulu, Kemampuan Awal Membaca Aksara...

maksimal sehingga penguasaan siswa terhadap kompetensi baca tulis aksara Jawa siswa belum maksimal.

Beberapa faktor yang menjadi penyebab kemampuan membaca aksara Jawa siswa rendah yaitu antara lain kurang minatnya siswa untuk mempelajari aksara Jawa, terbatasnya kreativitas guru dalam penggunaan media untuk membelajarkan aksara Jawa, ditambah dengan aksara Jawa yang jarang digunakan dalam kehidupan seharihari, merupakan faktor yang menjadikan siswa kesulitan dalam mempelajari, memahami,dan menghafal aksara Jawa.

Selain itu, alokasi waktu yang disediakan untuk matapelajaran Bahasa Jawa setiap minggunya dalam praktik di lapangan (sekolah) tergolong singkat, sedangkan cakupan materi Bahasa Jawa tidak sedikit. Selain itu pembelajaran membaca dan menulis aksara Jawa merupakan materi dalam mata pelajaran Bahasa Jawa yang sulit. Rata-rata dikarenakan siswa belum bisa menghafal huruf-huruf dalam aksara Jawa. Selain itu, hal tersebut juga dipengaruhi oleh tidak adanya media pendukung yang menarik dan memudahkan siswa dalam mempelajari materi aksara Jawa.

Berdasarkan hasil analisis kemampuan awal membaca aksara Jawa tersebut, maka salah satu cara yang bisa dilakukan adalah dengan mengembangkan media, karena salah satu fungsi media adalah sebagai alat bantu mengajar dan dapat membuat pembelajaran lebih menarik. Ada beberapa media yang dapat digunakan di dalam pembelajaran, salah satu diantaranya adalah dengan memanfaatkan teknologi komputer.

Perkembangan teknologi komputer terutama dalam bidang perangkat lunak yang makin pesat, sangat mendukung dalam penerapannya sebagai media pembelajaran. Media pembelajaran tentang aksara Jawa dapat dibuat dengan memanfaatkan teknologi komputer. Pembelajaran dengan menggunakan teknologi komputer diharapkan dapat membantu siswa memahami materi tentang aksara Jawa, karena dengan komputer memungkinkan untuk menghadirkan bentuk pembelajaran yang menarik. Melalui pemanfaatan teknologi komputer dapat disajikan media pembelajaran yang memuat materi pembelajaran secara visual, audio, audiovisual maupun multimedia.

\section{KESIMPULAN}

Berdasarkan hasil penelitian dan analisis data, yang diperoleh dari penelitian ini, maka dapat disimpulkan bahwa hasil analisis menunjukkan bahwa kemampuan membaca aksara Jawa siswa kelas IV SDN Kutorejo I Tuban masih rendah. Adapun solusi yang dapat ditawarkan adalah dengan mengembangkan media, karena salah satu fungsi media adalah sebagai alat bantu mengajar dan dapat membuat pembelajaran lebih menarik. Melalui pemanfaatan teknologi komputer dapat disajikan media pembelajaran yang memuat materi pembelajaran secara visual, audio, audiovisual maupun multimedia. 
Wendri, Mega, Lulu, Kemampuan Awal Membaca Aksara...

\section{DAFTAR RUJUKAN}

Arikunto, S. 2010. Prosedur Penelitian .Jakarta: RinekaCipta

Indrawan, S. 2014. Upaya Meningkatkan Keterampilan Membaca Aksara Jawa dengan Quantum Learning di Kelas VB SD 1 Kadipiro Bantul. Skripsi. Yogyakarta: UNY.

Prihantoro, D. 2011. Sejarah Aksara Jawa. Jakarta: Javalitera.

Tarigan, H., G. 2008. Menulis sebagai Suatu Keterampilan Berbahasa .Bandung: Angkasa. 